\title{
POSSIBILITY OF TEMPORAL VARIATIONS IN EARTH TIDAL STRAIN AMPLITUDES ASSOCIATED WITH MAJOR EARTHQUAKES
}

\author{
Takeshi Mikumo, ${ }^{*}$ Masaaki Kato, ${ }^{*}$ Hikaru Dor, ${ }^{*}$ Yasuo Wada, ${ }^{*}$ \\ Torao TANAKA, ${ }^{*}$ Ryuichi SHICHI, ${ }^{* *}$ and Akihiko YAMAMOTo*** \\ *Disaster Prevention Research Institute, Kyoto University, \\ Uji, Kyoto, Japan \\ **Faculty of Science, Nagoya University, Nagoya, Japan
}

(Received April 8, 1977)

\begin{abstract}
Earth tidal strains observed concurrently at two stations in the western Chubu region have been analyzed to see if there are any temporal variations of their amplitude in relation to major earthquakes in the region.

The tidal strain records obtained at Kamitakara during 7 years and at Inuyama during 2 years are bandpass-filtered, and correlated with the corresponding theoretical tidal function predicted for a solid earth, using least squares mainly in the time domain, to estimate the tidal admittance over the periods. The admittances determined for the two-component Kamitakara strains appear to show a consistent and gradual increase during 10-11 months prior to the central Gifu earthquake of $1969(M=6.6)$, with a maximum variation reaching about $15 \%$, and after the earthquake they seem to decrease and recover their normal value a half year later. No such significant variations as in this period can be found over the entire period. The resolved amplitudes of the semidiurnal $\mathrm{M}_{2}$ and diurnal $\mathrm{O}_{1}$ waves show similar trends. The results from the Inuyama observations involve somewhat larger fluctuations, but appear to reach a peak 3-4 months before the earthquake and then decrease to the time of its occurrence.

Secular strains and tilts observed at the above two stations also indicate appreciable changes during the corresponding periods. If these temporal variations of the tidal strain amplitudes are not spurious but real phenomena, they might be interpreted as a manifestation of some precursory changes in crustal rigidity around the seismic source region.
\end{abstract}

\section{Introduction}

The possibility of temporal variations in the earth tidal amplitudes associated with earthquakes has first been suggested by Nishimura (1950). He found unusual fluctuations of the tidal tilt amplitudes observed at Makimine in eastern Kyushu, and related them to variations in seismic activity in the Hyuganada region where large thrusting earthquakes had taken place repeatedly, suggesting appreciable changes in crustal elasticity around there. Some part of the large fluctuations, however, may probably be attributed to some instrumental instability.

Recent theoretical studies made by BEAUMONT and BERGER (1974) indicate that 
the amplitude of tidal strains and tilts could change by as much as $60 \%$ if seismic $\mathrm{P}$ wave velocity decreases by $15 \%$ in a dilatant zone embedded within the crust. They suggested that the amplitude changes could be detected to a distance of 1.5 times the typical dimension of the dilatant inclusion, and that their time dependence would be similar to that of the $V_{p} / V_{s}$ ratio if such dilatancy actually precedes major earthquakes. TANAKA and Kato (1974) made a preliminary estimate of possible changes of the ocean-tide loading response due to dilatancy assumed in coastal regions. More complete calculations made by TANAKA (1976), applying a two-dimensional finite element technique to possible dilatant zones with different shapes and dimensions extended underneath the coast, show that the amplitude changes in the $M_{2}$ wave could reach the order of $10 \%$ of its normal value even at $25 \mathrm{~km}$ inland from the coastal line, in case of a sea-level rise of $50 \mathrm{~cm}$. This type of mechanism would be superposed in coastal regions on the direct effects of dilatancy on solid-earth tides.

Besides the above studies, only few observations of the earth tide amplitudes have been reported to date in relation to earthquakes. From the analysis of the tidal strains observed at a station in the zone of the Kondarinsky fault, LATYNINA and RIZAEVA (1976) showed that the amplitude of the semidiurnal $\mathrm{M}_{2}$ wave in a direction across the fault decreased by $6 \%$ about one month before the Luchobsky earthquake in $1967(M=4.5, h=10 \mathrm{~km}, \Delta=20 \mathrm{~km})$ in South Tien Shan, and that it increased to its normal value at the time of the earthquake. The other strain component, however, in the direction parallel to the fault remained constant within its accuracy.

It was also reported that there was appreciable increase in the tidal factor of gravity, up to 1.6 , several days after the 1974 Off-Izu Peninsula earthquake $(M=$ $6.8, \Delta=15 \mathrm{~km}$ ) (EARThQUaKe Research Institute, 1975), but no significant variations prior to the earthquake have been detected. Hosoyama (1976) investigated the tidal tilt amplitude observed in 1968-1974 at the Akagane station in the Tohoku region, and did not find any correlations to seismic activity in a region within a distance of $300 \mathrm{~km}$, although there were only a few earthquakes which seemed likely to give small effects to the observations.

Thus, there has been actually no convincing evidence of remarkable variations in the earth tide amplitude prior to major earthquakes with greater magnitudes, even though such precursory changes have been suggested by theoretical investigations. In the present paper, we attempt to analyze long-term earth tidal strain records concurrently observed at two different stations by applying a somewhat refined method, to see if there are any temporal variations in their amplitudes as well as secular strains in relation to two major earthquakes which have recently occurred in the western Chubu region, Japan.

\section{Observations and Analyses of Earth Tidal Strains}

The western Chubu region is characterized geologically by the existence of a number of active Quaternary faults trending in the NNW-SSE and NE-SW directions, 


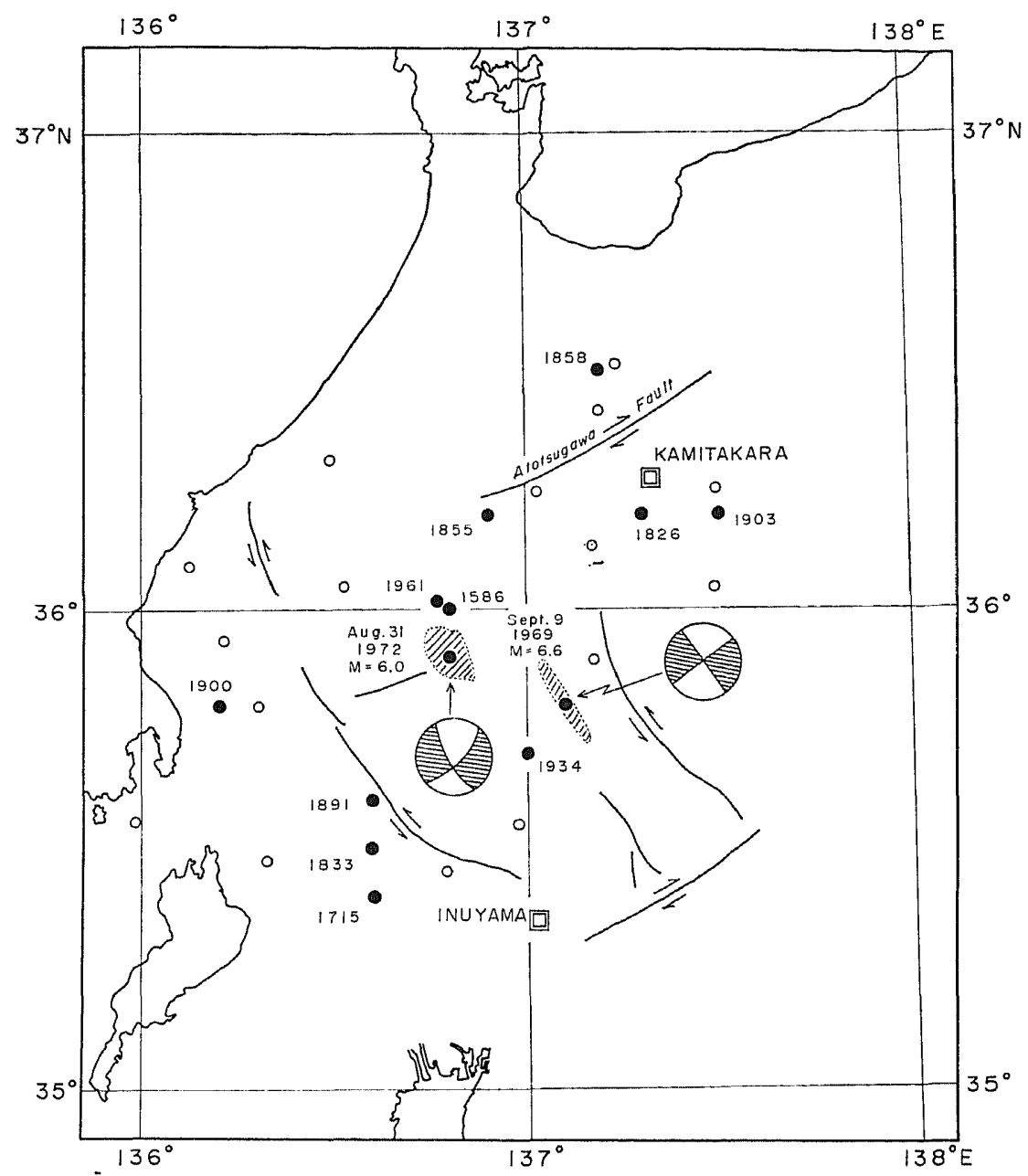

Fig. 1. Location of major earthquakes (solid circles with numerals), observation stations (double squares for crustal movement observatories and small open circles for highsensitive seismograph stations), and active Quaternary faults (thick lines with arrows indicating slip directions) in the western Chubu region. Fault plane solutions and aftershock areas of the 1969 and 1972 earthquakes are also shown.

which are believed to have been formed by compressional tectonic stress in an E-W trend, and also noted for high seismic activity along these faults (See Fig. 1). The largest earthquake that took place in recent years within this region was the central Gifu earthquake of September 9, $1969(M=6.6)$, which indicated left-lateral strikeslip mechanism with dimensions of $20 \mathrm{~km}$ by $10 \mathrm{~km}$ and average fault displacement of $70 \mathrm{~cm}$ (Mikumo, 1973). Another remarkable one was the Fukui-Gifu border earthquake of August 31, $1972(M=6.0)$ with a similar mechanism. In Fig. 1 are shown their locations, fault-plane solutions and aftershock areas.

In this region, the observations of crustal strains and tilts have been continued 
since 1966 at two main stations (double squares in Fig. 1); one is the Kamitakara Crustal Movement Observatory of Kyoto University which is located close to the Atotsugawa fault in the northern area, and the other is the Inuyama Seismological and Crustal Movement Observatory of Nagoya University close to the southeastern end of the Neodani fault in the southern area. The epicentral distances from the Kamitakara station to the above two earthquakes are about 50 and $60 \mathrm{~km}$, and those from the Inuyama station are about 50 and $65 \mathrm{~km}$, respectively. Both stations are equipped with three components of quartz-tube strainmeters $(28-30 \mathrm{~m})$, two components of water-tube tiltmeters $(30 \mathrm{~m})$ and several sets of horizontal pendulum tiltmeters, all of which are installed in deep vaults composed of Paleozoic basement rocks. For the present purposes we use the Kamitakara strain records which have been obtained during the periods January, 1967-December, 1972 and September, 1974-September, 1976 by the three components-E1 (NE-SW), E2 (NW-SE), and E3 (N-S)-strainmeters (sensitivity about $3.5 \times 10^{-9} / \mathrm{mm}$, recorded maximum tide amplitude $2 \mathrm{~cm}$ on photographic recording with a paper speed $3 \mathrm{~mm} / \mathrm{hr}$, Dor et al., 1976) and also the Inuyama records for the period from September, 1968 to May, 1970 obtained by the E-W and NW-SE component strainmeters (sensitivity about $3.3 \times 10^{-9} /$ digit, recorded maximum tide amplitude $1 \mathrm{~cm}$ on ink-writing recording with a paper speed $20 \mathrm{~mm} / \mathrm{hr}$, IIDA et al., 1969).

The observed strain records involve earth tides, secular ground deformations, meteorological and some other disturbances. The short-period noise and long-term variations outside the tidal frequencies have been removed by bandpass filtering as

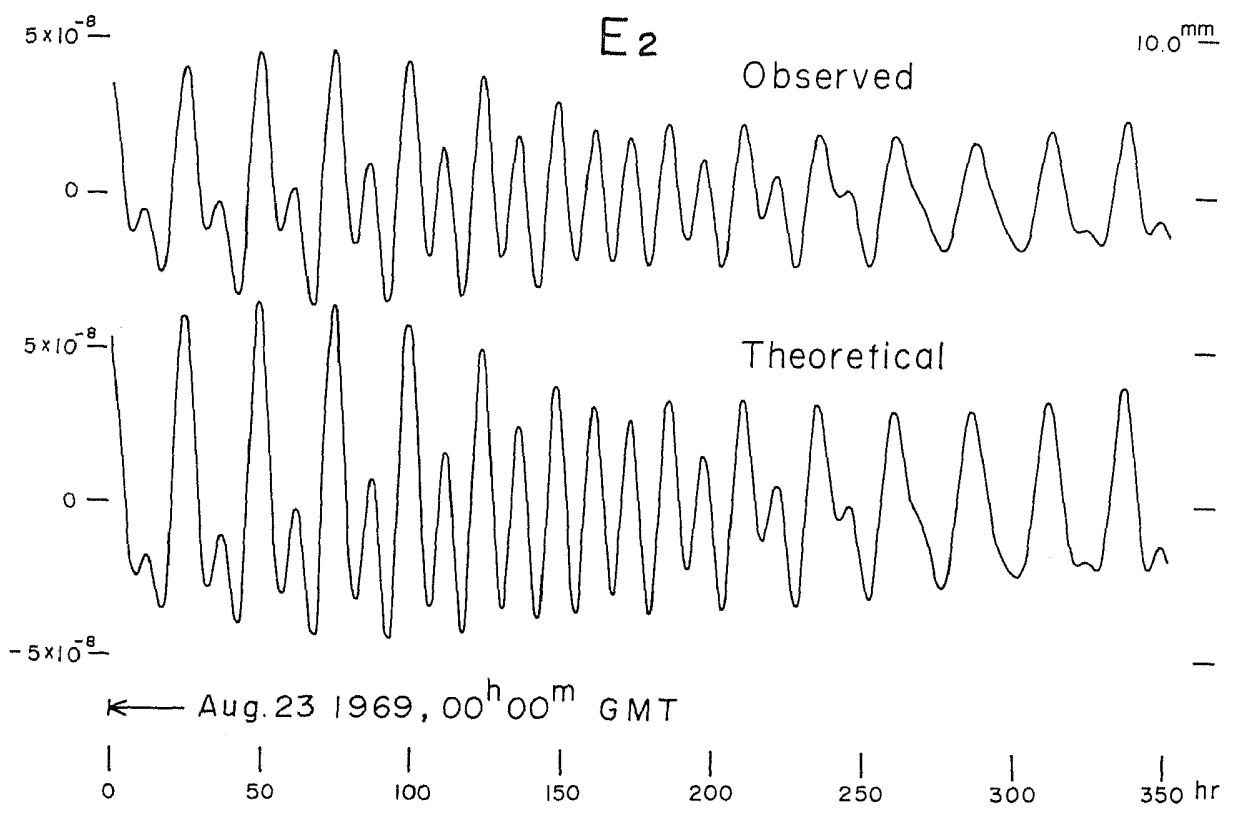

Fig. 2. An example of the filtered strain record obtained at the Kamitakara station and the corresponding theoretical tidal strain function for a solid earth. 
described in Mikumo and Nakagawa (1968) and Mikumo and Kato (1976). For the Inuyama records, provisional processing has also been applied by a low-pass filter as used by SHICHI (1973) prior to the above bandpass filtering. For the determination of the tidal strain amplitudes, we use the following two methods. One is the conventional least squares technique applied directly to the filtered records, which yields the amplitude and phase at particular frequencies appropriate to major tidal constituents, such as $\mathrm{M}_{2}$ and $\mathrm{O}_{1}$ waves. The alternative mainly used in the present paper is a sort of the time domain analysis, which correlates the filtered records with the corresponding theoretical tidal strain functions for a laterally homogeneous solid earth, without resolving the records into a number of constituents. The direct comparison between the observed and theoretical tides using least squares in the time domain yields the overall tidal admittance (the amplitude ratio and time delay) averaged over all tidal frequencies, as has been described in detail by Mrkumo and Kato (1976). Figure 2 shows an example of the filtered record obtained at the Kamitakara station and the theoretical tidal strains for the period in AugustSeptember, 1969 just prior to the Gifu earthquake. Good agreements in the wave-
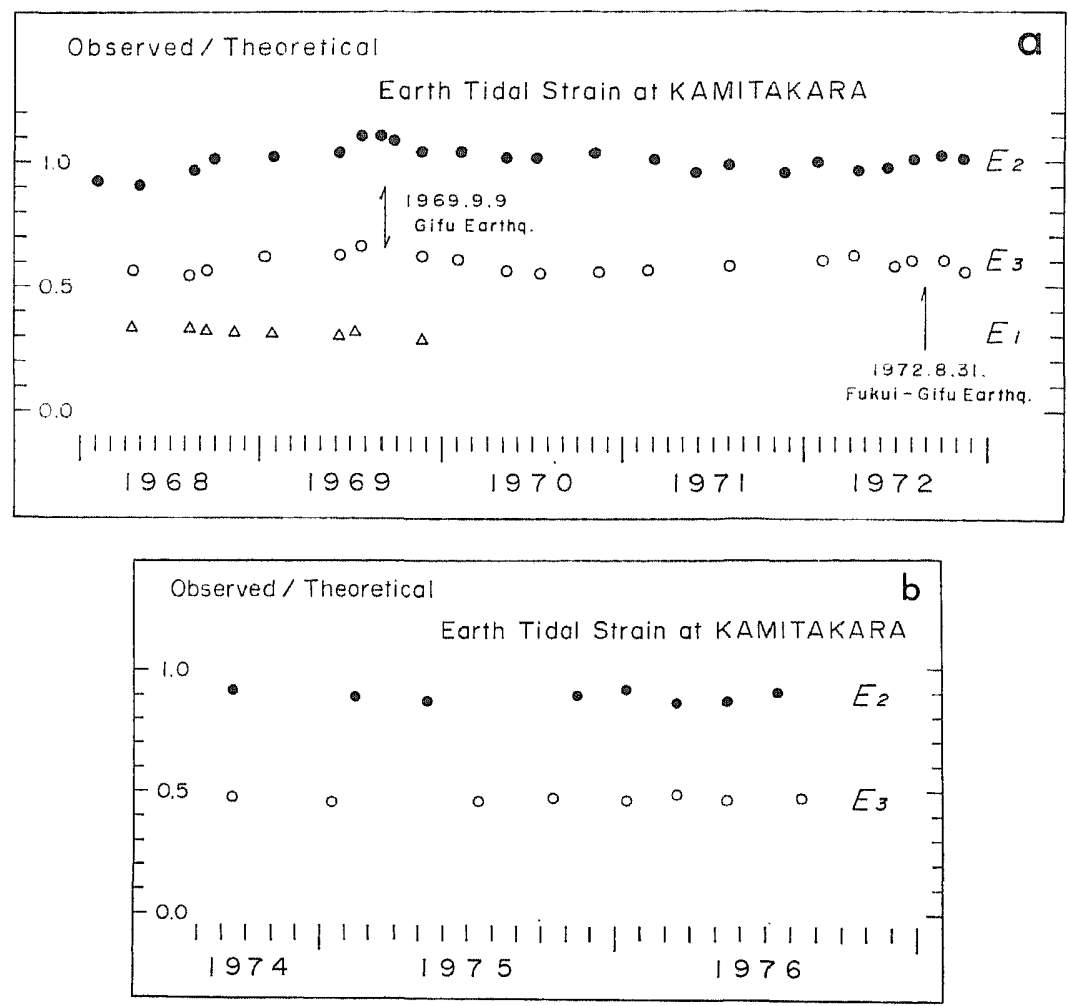

Fig. 3. Tidal admittance determined from the Kamitakara observations: (a) for the period during 1968-1972, (b) for the period during 1974-1976. E1, E2, and E3 indicate the NE-SW, NW-SE, and S-N strain components. The same symbols are used in Figs. 4 and 5 . 
forms between the two traces may be considered to assure a reliability of the results from the time domain analysis. The amplitude ratio and time lag computed in this case are $1.1033 \pm 0.0064$ and $0.246 \pm 0.009 \mathrm{hr}$, respectively.

\section{Results}

The present analysis has been applied to appropriately sampled time intervals during the observation periods. Each of the sampled intervals usually contains more than 29 days, but had to be restricted to 15-25 days in several cases when some part of the records has been disturbed or interrupted by rainfalls and some other noise.

Figures 3(a) and 3(b) show the determined amplitude ratios of the observed to theoretical strains for the Kamitakara observations in 1968-1972 and 1974-1976, respectively. It is noticed from the figures that the ratios for both the E2 and E3 components have some long-period fluctuations during the former period particularly between late 1968 and mid-1970 while they remain almost constant between 1974 and 1976. The probable errors calculated for each of the plotted points are less than $1 \%$, and the R.M.S. standard deviation of all points over the entire period are estimated to be 3.8 and $4.2 \%$ for the two components respectively, with an average time lag of $0.22 \mathrm{hr}$. The two major earthquakes have taken place during the former period. From closer examinations of the fluctuations, it appears that the amplitude ratios for the two components show a consistent and gradual increase about 10-11 months prior to the 1969 earthquake, with a maximum variation reaching about $15 \%$, more than 3 times the standard deviation, and that after the earthquake they begin to decrease and then recover to their normal value about a half year later. It also appears that no such large variations as in this period can be found over the entire period, although there are some slight fluctuations within the standard deviation around the time of the 1972 earthquake.

Figures 4 and 5 show the corresponding resolved amplitudes of the semidiurnal $\mathrm{M}_{3}$ and diurnal $\mathrm{O}_{1}$ waves at Kamitakara, where only the results from the data with time intervals longer than 20 days are plotted. Standard deviations of their fluctuations are $3.5\left(\mathrm{M}_{2}\right)$ and $5.8 \%\left(\mathrm{O}_{1}\right)$ for the E2-component and $5.2\left(\mathrm{M}_{2}\right)$ and $4.9 \%\left(\mathrm{O}_{1}\right)$ for

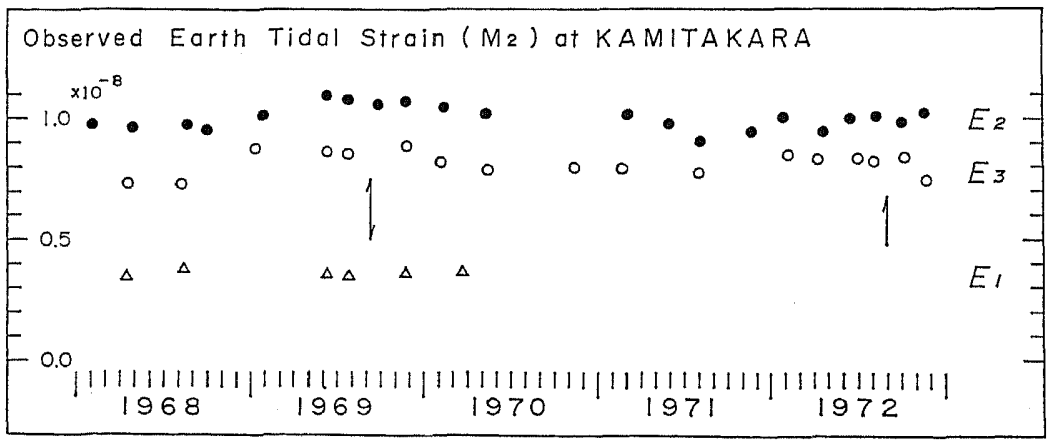

Fig. 4. Observed tidal strain amplitudes of the semidiurnal $\mathrm{M}_{2}$ wave at Kamitakara. 
the E3-component, respectively. These fluctuations appears, however, considerably larger than those in the case of the overall tidal admittance. This may be due to the fact that the resolution of the tidal spectrum is easily affected by truncation of the analyzed records and often contaminated by some leakage of power at neighbouring

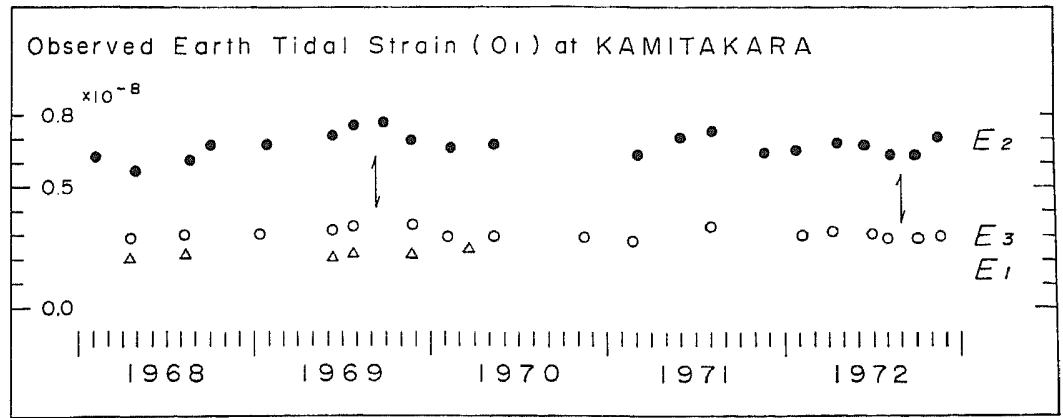

Fig. 5. Observed tidal strain amplitudes of the diurnal $\mathrm{O}_{1}$ wave at Kamitakara.

Tidal Phasor Plots $\left(M_{2}\right)$ for Kamitakara
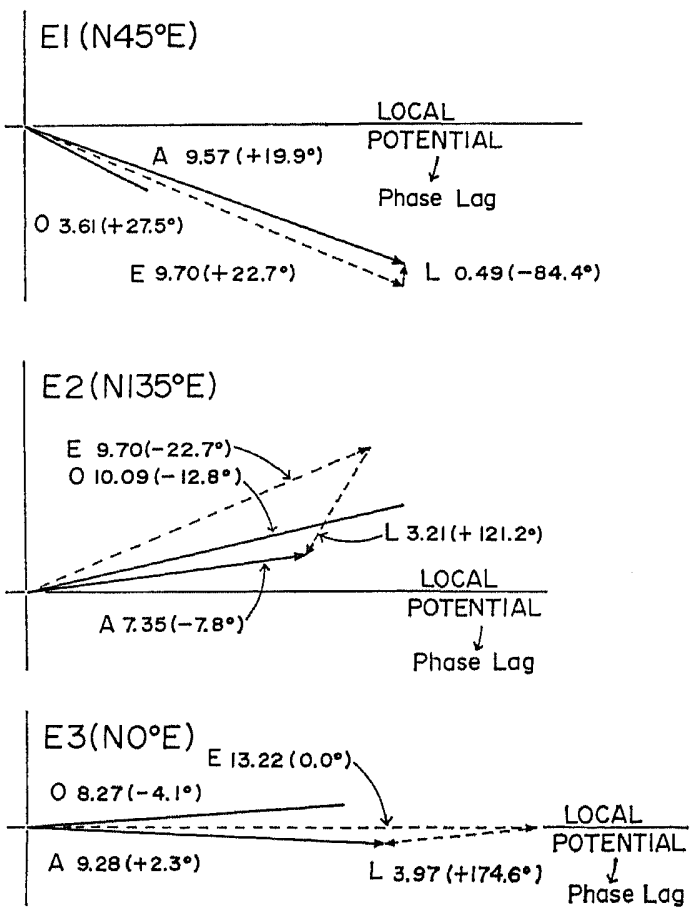

Fig. 6. Tidal phasor plot of the $\mathrm{M}_{2}$ wave at Kamitakara. E, theoretical strains for a solid earth; $L$, contribution from the ocean tide loading (computed by $\mathrm{T}$. Tanaka); $\mathrm{A}$, the synthesized tidal strains; $\mathrm{O}$, the observed tidal amplitude. 
frequencies. Nevertheless, similar increase of the amplitudes seems to be still noticed around the time of the 1969 earthquake as in Fig. 3(a), which is sufficiently over the standard deviations. The E1-component does not indicate such fluctuations between 1968 and 1969 as in the other two components, but its recorded amplitudes are rather small to be discussed with the same confidence level.

It is to be mentioned here that there are remarkable differences in the amplitude ratios among the three components, as well as their departures from unity (Fig. 3). Some part of the differences may be attributed to the effects of ocean tide loading, since it is well known that oceanic tides have much influences on earth tides except in the midst of the continents. The loading effects of ocean tides on $M_{2}$ wave at the Kamitakara station have been numerically estimated by Tanaka using the Green's function by FARRELL (1972) for the Gutenberg-Bullen A earth model (TANAKA, 1974). The results are illustrated in Fig. 6 in the form of phasor plot, which indicate that the effects could reach about $30 \%$ of solid earth tides but are not sufficient to account for the above discrepancy. Other probable sources would be cavity and topographical effects as has been calculated by HARRISON (1976), since surface topography around the Kamitakara observation vault appears rather complicated as shown in Fig. 7. Since we are mainly concerned here with temporal variations in the tidal admittance, more detailed discussion on the absolute amplitude level will be made elsewhere. Slight differences in the average amplitude ratio between the two periods in Figs. 3(a) and 3(b) are due to some alteration of our observation system.

The tidal admittance for the strains observed at the Inuyama station are shown in Fig. 8, which have been determined by the time domain analysis. The computed results involve somewhat larger fluctuations with the standard deviation of 5.0 and $7.2 \%$ for the E-W and NW-SE components, respectively. A part of the fluctuations might be due to some instrumental instability, particularly for the E-W component after February, 1970. If all points after this period are excluded, the amplitude ratio in the two components would appear to increase consistently by about $10 \%$

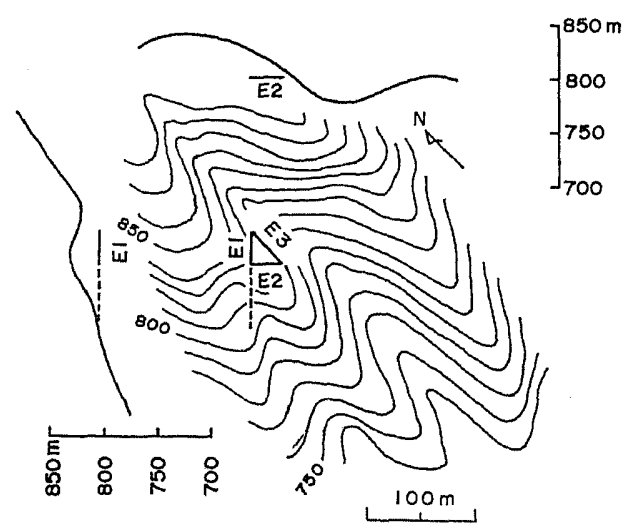

Fig. 7. Topography around the Kamitakara observation vault. Thick lines indicate surface elevation along the direction of the relevant strainmeters. 


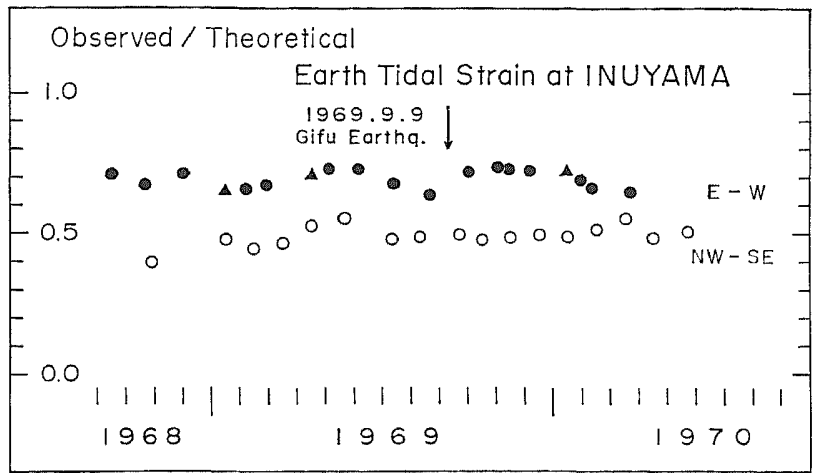

Fig. 8. Tidal admittance determined from the Inuyama observations for the E-W and NW-SE strain components.

from February to June, 1969 and then decrease to August just before the 1969 earthquake. The E-W component seems to recover somewhat higher values after the earthquake. These variations, however, may not be regarded as convincing, in view of more scattered results in a later period not shown here. It is noticed that there is some phase difference in the increasing trend of the admittance as compared with that for the Kamitakara station even if the variations are true.

\section{Discussion}

From the above described results, we are not convinced but inclined to have a view that the observed temporal variations in the tidal strain amplitudes, at least, at the Kamitakara station are not spurious but probably real phenomena associated with the 1969 earthquake. If this is the case, it would then be necessary to investigate several possibilities for the cause of the variations, such as some changes in oceanic tide loading, tectonic stress field and in crustal rigidity, etc.

The possibility of time variations in the ocean tide loading have been examined here from the tide gauge records obtained during the period from April, 1968 to August, 1970 on the coast of the Toyama bay about $55 \mathrm{~km}$ north of Kamitakara. The results by least squares analysis do not indicate any significant changes in the oceanic $\mathrm{M}_{2}$ and $\mathrm{O}_{1}$ waves within their accuracy (6-8\%), suggesting no close relations to the observed temporal variations in the Kamitakara strain amplitudes.

Secular ground strains observed at the Kamitakara station (Dor et al., 1976) are shown in Fig. 9. It is directly noticed that the observed strains, particularly of the E1-component parallel to the direction towards the 1969 epicenter, and also areal and principal strains, turned to remarkable compression around late 1968, which continues to early 1970 . Noticeable tilt changes from $\mathrm{S} 70^{\circ} \mathrm{E}$ to $\mathrm{S} 80^{\circ} \mathrm{W}$ direction have also been recorded by water-tube tiltmeters at this time (DoI et al., 1976). At the Inuyama station, it has been found that secular strain rates were accelerated to extension (SHICHI and IIDA, 1973) and tilt movements changed their 


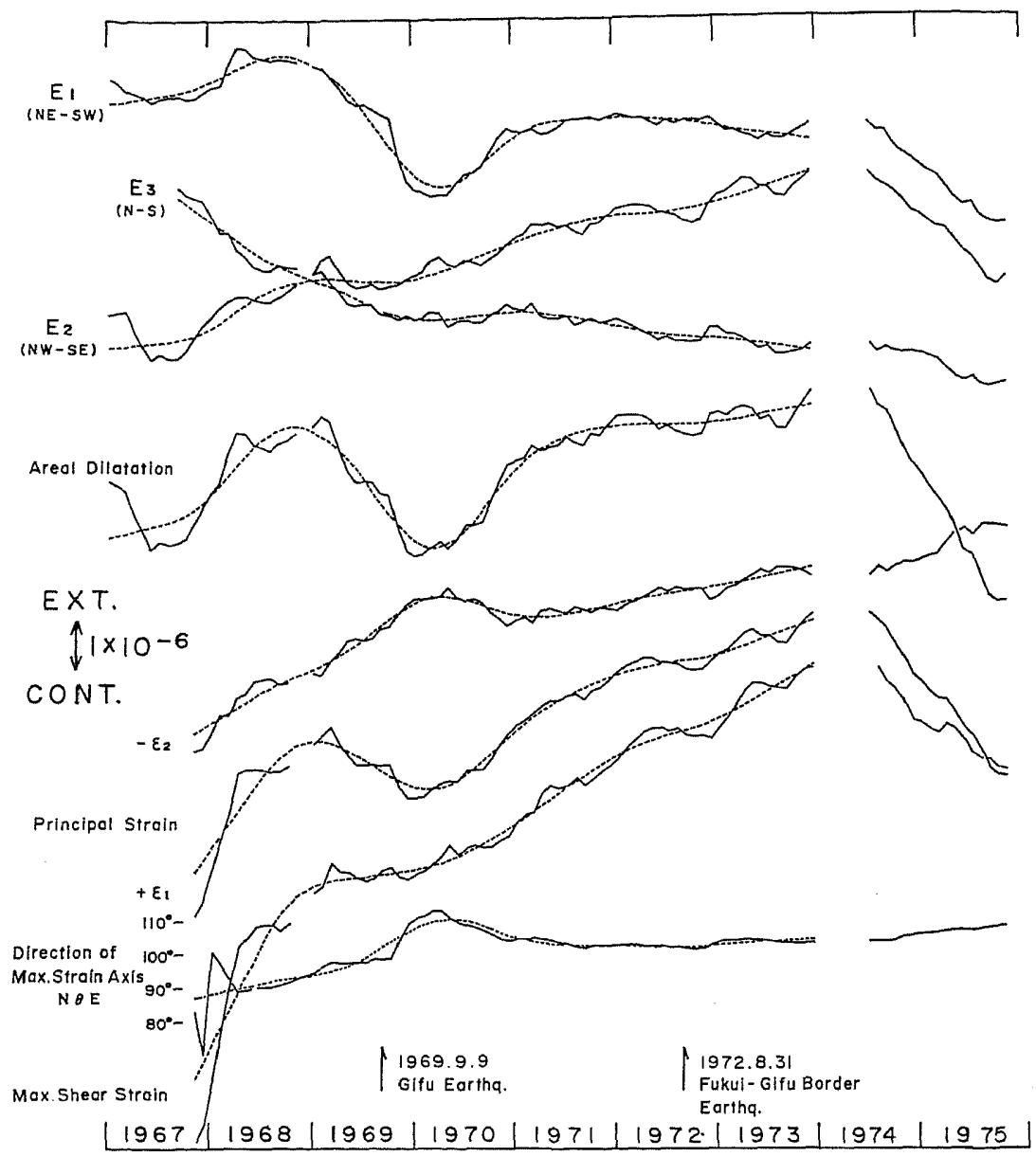

Fig. 9. Secular ground strains observed at Kamitakara (after Dor et al., 1976).

rates towards $\mathrm{N} 35-40^{\circ} \mathrm{W}$ direction around January, 1969 (SHICHI, 1973). Geodimeter measurements near the Atera fault about $25 \mathrm{~km}$ east of the epicenter also indicated appreciable extensional strain changes similar but in a reverse sense to the case of Kamitakara (SHibano, 1976). These nearly consistent observations appear to suggest that rather wide but asymmetric changes in the strain and tilt fields occurred over this region around late 1968 to early 1969. Around the time of the 1969 earthquake, both the strain and tilt rates at the two stations reached their peak values, and thereafter the Kamitakara compressional strains still increased up to early 1970, while the Inuyama extensional strains were decelerated to their original state (SHICHI, 1973; SHICHI and IrDA, 1973; Dor et al., 1976). The average strain rates were highest with $3 \times 10^{-6} /$ year during November, 1968-February, 1970 at Kamitakara and $5 \times 10^{-6} /$ year during January-September, 1969 at Inuyama, respectively. It is interesting to note that the observed temporal increase and recovery of the tidal strain amplitudes at the two stations, if they are real, appear to correspond 
approximately to the above periods. The high strain rates might be a manifestation of the state of rapid increase of microcracks as well as of total deformation or dilatancy of relevant volume of rocks (e.g., MJACHKIN et al., 1975; BRADY, 1974) under the observation sites. This could lead to a decrease in crustal rigidity and hence an increase in the tidal strain amplitude, as have been suggested by BEAUMONT and BERGER (1974).

Leveling surveys made across the source region of the 1969 earthquake revealed gentle ground uplifting in the southwest and southeast side of the fault zone between 1944 and 1966 up to three years before the earthquake, and slight subsidence in the northwest region during the same period (TANAKA and Tsukahara, 1973). These trends do not indicate a uniform dilatancy as proposed by ScHolz et al. (1973), but suggest, at least, some concentration of tectonic stresses there at this early time. It has been reported, on the other hand, that there was some decrease in seismic Pwave velocity in late 1965 (UTSU, 1975) and in the $V_{p} / V_{s}$ ratio in early 1967 (MrzUTANI et al., 1973) more than two and a half years before the earthquake, although

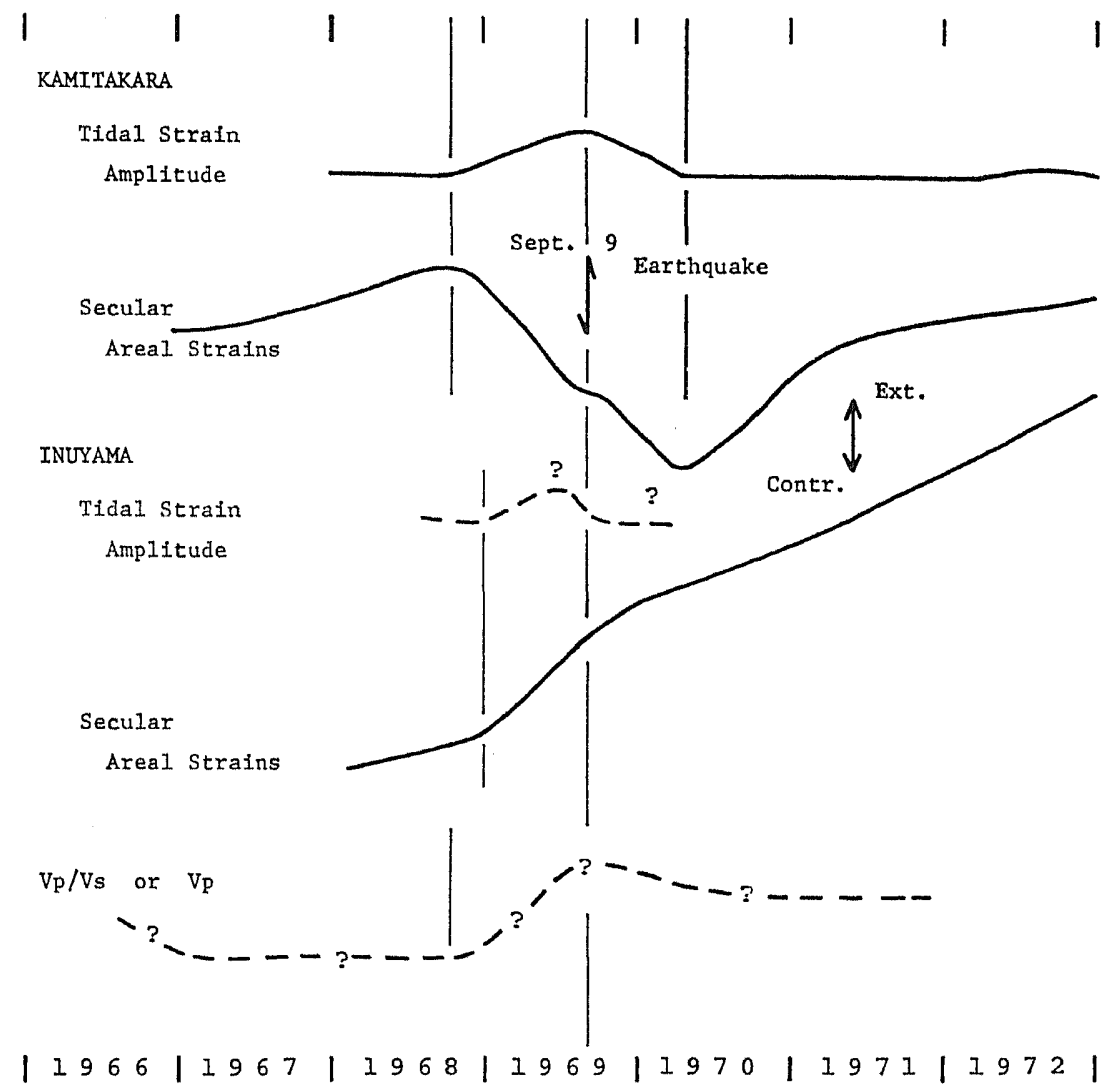

Fig. 10. Schematic representations of temporal variations in the tidal strain amplitudes (this paper), secular areal strains (Dor et al., 1976; SHICHI and IIDA, 1973), and in seismic wave velocity (Mrzu TANI et al., 1973; UTsu, 1975). 
their data showed considerable scattering. If these velocity decreases are true, it would follow that dilatancy phenomena might have already taken place in the source region around this period, and that the changes in the tidal amplitudes as well as in the crustal strains emerged in a much later period of late 1968 to early 1969 when the low velocity began to return to its normal value. These situations are schemam tically depicted in Fig. 10.

We now attempt to offer some tentative interpretations here assuming that all these observations reflect real changes in crustal properties.

1) At an early stage, seismic velocity decreases only in a limited source region where a sort of dilatancy develops due to the formation of microcracks and their interactions (e.g., MJACHKIN, 1975). Any detectable changes do not take place yet in surrounding regions.

2) The source dilatancy extends gradually, probably at very low speeds in a form of anelastic deformations (cf., YAMADA, 1973; IsHIr, 1976), towards the surrounding regions (e.g., Wyss, Interpretation of the southern California uplift in terms of the dilatancy hypothesis (preprint), 1977) where volumetric deformations then begin to occur and crustal elasticity decreases as in the early stage in the source region. This will cause observable changes in crustal strains and tidal amplitudes there in somewhat delayed periods. The direction of their changes will be specified by geological and topographical conditions of observation sites. In the source region at this stage, unstable slips due to further formation of large cracks take place and the decreased seismic velocity begins to recover (MJACHKIn et al., 1975). The preseismic slip movements produce elastic changes of the strain and tilt fields in the surrounding region, and this effect will be superposed on the delayed anelastic deformations. Actually, it has been pointed out that the directions of the secular strain and tilt changes observed at three sites in late 1968 to early 1969 are nearly consistent with those accompanied by coseismic fault movements (Mrkumo, 1973; Dor et al., 1976).

3) The fault displacement at the time of the 1969 earthquake yielded compressional areal strains on both the Kamitakara and Inuyama stations (Mikumo, 1973), which will have accelerated the compressional strains at Kamitakara but decelerated the extensional strains at Inuyama. This might give a possible explanation for the difference in a duration time of the increase in the tidal amplitudes between the two stations.

It is to be again stressed that the above descriptions are only speculative and would have to be considerably modified when more information is obtained. Also, it is undoubtedly necessary to verify from much more observations with higher accuracies if temporal veriations in the earth tidal amplitude actually exist in relation to larger earthquakes. It is expected that these studies will give a clue for searching possible changes in crustal properties and hence for predicting earthquakes, since the earth tides are temporally continuous and spatially deterministic input signal as pointed out by BEAUMONT and BERGER (1974). 
We wish to thank Dr. Kazuo Oike and Dr. Kennosuke Hosoyama for providing their own data or results in advance of publications, and Dr. Ichiro Nakagawa for allowing us to use his computer program for the least squares tidal analysis. Our thanks are also due Makoto Koizumi, Yoshinobu Hoso and Ritsuko Koizumi for their assistance in the course of the present work.

Computations involved were made at the Data Processing Center, Kyoto University and the Computer Center, Nagoya University.

\section{REFERENCES}

Beaumont, C. and J. Berger, Earthquake prediction: Modification of the earth tide tilts and strains by dilatancy, Geophys. J., 39, 111-121, 1974.

BraDy, B. T., Theory of earthquakes. I. Scale independent theory of rock failure, Pageoph, 112, 701723,1975 .

Dor, H., M. KATO, Y. WADA, and T. Mrkumo, Observations of crustal strains and tilts at the Kamitakara Crustal Movement Observatory, J. Geod. Soc. Japan, 22, 1976 (in Japanese).

EARTHQUAKE RESEARCH INSTITUTE, Changes in tidal factor during the 1974 Izu-Hanto-Oki earthquake by means of an Askania tidal gravimeter, Rep. Coord. Comm. Earthq. Predict., 13, 67-68, 1975 (in Japanese).

Farrell, W. E., Deformation of the earth by surface load, Rev. Geophys. Space Phys., 10, 761-7.97, 1972.

Harrison, J. C., Cavity and topographic effects in tilt and strain measurement, J. Geophys. Res., 81, 319-328, 1976.

Hosoyama, K., Characteristics of ground tilts at the Akagane station, read at Annu. Meet. Geod. Soc. Japan, October, 1976.

IIDA, K., R. Shichi, and H. MatsuUra, Observation of crustal deformation at Inuyama, J. Geod. Soc. Japan, 14, 144-155, 1969 (in Japanese).

IsHri, H., Continuous multipartite observations of crustal movements in the Tohoku region, read at Annu. Meet. Seismol Soc. Japan, October, 1976.

LATyNinA, L. A. and S. D. Rizaeva, On tidal-strain variations before earthquakes, Tectonophysics, 31, 121-127, 1976.

Mikumo, T. and I. NakAGAwa, Some problems on the analysis of the earth tides, J. Phys. Earth, 16, $87-95,1968$.

Mıкumo, T., Faulting mechanism of the Gifu earthquake of September, 9, 1969, and some related problems, J. Phys. Earth, 21, 191-212, 1973.

Mikumo, T. and M. Kato, Time domain analysis of earth tide records, Bull. Disast. Prev. Res. Inst., Kyoto Univ., 26, 71-81, 1976.

Mizutani, H., T. Ishido, and T. Matsui, Time variations in the $\Delta t_{p} / \Delta t_{8}$ ratio in the epicentral region of the central Gifu earthquake, read at Annu. Meet. Seismol. Soc. Japan, November, 1973.

Mjachkin, V.I., W. F. Brace, G. A. Sobolev, and J.H. Dieterich, Two models for earthquake forerunners, Pageoph, 113, 169-181, 1975.

Nishimur a, E., On earth tides, Trans. Am. Geophys. Union, 31, 357-376, 1950.

Scholz, C. H., L. R. Sykes, and Y.P. Aggarwal, Earthquake prediction: A physical basis, Science, 181, 803-810, 1973.

Shibano, M., Results of geodimeter measurements in the Atera fault area, read at Geod. Soc. Japan, October, 1976.

Shrchi, R., Long period crustal deformation, J. Geod. Soc. Japan, 19, 213-224, 1973 (in Japanese).

SHICHI, R. and K. IIDA, Observation of crustal deformation at Inuyama (III), J. Geod. Soc. Japan, 19, 8-21, 1973 (in Japanese).

TANAKA, T., Tidal tilts and strains, and oceanic tides (Part 4), J. Geod. Soc. Japan, 20, 36-41, 1974 (in Japanese).

TANakA, T., Effect of dilatancy on ocean load tides, Pageoph, 114, 415-423, 1976.

TANAKA, T. and M. KATO, On the change of crustal elasticity and earth tides, J. Geod. Soc. Japan, 20, 125-132, 1974. 
S 136 T. Mikumo, M. Kato, H. Dor, Y. Wada, T. Tanaka, R. Shichi, and A. Yamamoto

TANaka, M. and K. Tsukahara, Crustal movements in the epicentral area of the Gifu earthquake of September 9, 1969, J. Geod. Soc. Japan, 19, 145-159, 1973 (in Japanese).

UTSU, T., Detection of a domain of decreased P-wave velocity prior to an earthquake, J. Seismol. Soc. Japan, II, 24, 435-448, 1975 (in Japanese).

Yamada, J., A water-tube tiltmeter and its applications to crustal movement studies, Rep. Earthq. Res. Inst., 10, 1-174, 1973 (in Japanese). 